\title{
Individual, Social, Economic, and Environmental Model: A Paradigm Shift for Obesity Prevention
}

\author{
Anura Amarasinghe ${ }^{1}$ and Gerard D'Souza ${ }^{2}$ \\ ${ }^{1}$ Analytical Services Branch, Australian Bureau of Statistics Locked Bag 10, Belconnen, Canberra, ACT 2616, Australia \\ ${ }^{2}$ Division of Resource Management, West Virginia University, P.O. Box 6108, Morgantown, WV 26505-6108, USA
}

Correspondence should be addressed to Gerard D’Souza, gerrydee102@hotmail.com

Received 15 October 2012; Accepted 31 October 2012

Academic Editors: B. van Wijngaarden and B. Vicente

Copyright (C 2012 A. Amarasinghe and G. D’Souza. This is an open access article distributed under the Creative Commons Attribution License, which permits unrestricted use, distribution, and reproduction in any medium, provided the original work is properly cited.

\begin{abstract}
Obesity has joined the list of "wicked problems" with associated implications for public health, food security, and the entire food supply chain. This paper examines the possible causes, consequences, and policy implications, especially important in an environment of shrinking budgets. The causes of obesity are multifaceted and involve complex interactions; hence any successful prevention and mitigation strategy should identify the key factors and interactions thereof. We propose a dynamic and integrated individual, social, economic and environmental model (ISEEM) to accomplish this. Within this framework, the optimal mix of economic incentives, better education, and land use planning emerge as key factors in obesity prevention and mitigation and the promotion of healthier, more sustainable communities. The use of the ISEEM framework, involving a combination of strategies targeted to specific circumstances of individual communities and localities, could address this wicked problem in an environment characterized by increasing conflicts among budgets, heuristics, and politics.
\end{abstract}

\section{Introduction}

Despite decades of research, policy makers are still debating the causes, consequences, and much needed policy interventions to combat obesity. Obesity is reaching epidemic proportions especially in the developed and, more recently, in the developing world, where the problem is compounded by a myriad of socioeconomic, demographic, built, and natural environmental factors. According to the World Health Organization (WHO) over one billion adults around the globe are overweight and about 700 million of those are considered to be obese [1]. In the United States about $64 \%$ of adults aged $20-74$ are overweight and $30 \%$ of those are estimated to be obese $[2,3]$. Obesity, defined in terms of body mass index $(B M I)$, is a function of both height and weight. According to the National Institute of Health $(N I H)$ US guidelines, adults having a $B M I \geq 30\left(\mathrm{~kg} / \mathrm{m}^{2}\right)$ are considered obese, and those with a $B M I 25-29.9\left(\mathrm{~kg} / \mathrm{m}^{2}\right)$ are considered to be overweight. For children, a BMI at or above the 95th percentile, depending on age and sex-specific growth charts, is considered to be obese [4]. Overweight and obesity increase the risk of having other diseases, such as diabetes, cardiovascular diseases, and cancer $[5,6]$. Health care expenditures of obesity in the USA are reported to be in the range of \$11-14 billion for children and youth and \$ 75-90 billion for adults [7].

The increased burden has led to an intense debate to call for significant policy initiatives to prevent obesity $[8,9]$. While acknowledging the significance of the contributions of the medical field to control weight issues, the focus in this paper will be to contribute to the understanding of the obesity problem in the context of social, economic, and environmental perspectives and, in the process, to examine the socioeconomic and policy implications for health promotion. Most of the reviewed literature pertains to the USA and other developed countries although there are some implications for developing regions of the world. Given the moderate success of existing strategies we propose a novel integrated framework for obesity prevention.

Next, we present some perspectives on health and obesity in general, followed by six dimensions specifically related to obesity. These include: (1) trends in food consumption and 
eating habits, (2) poverty and food insecurity, (3) economic growth and technological developments, (4) time use, recreational and physical activity, (5) natural and built environment, and (6) obesity as a market failure. The final sections are dedicated to discussing the proposed ISEEM mechanism for obesity prevention.

1.1. Perspectives on Health and Obesity. Health, a form of human capital, can raise productivity of individuals, households, different market segments including labor, and the economy as a whole [10]. An individual's health can be influenced by both observed (e.g., lifestyle choices) and unobserved heterogeneous components (e.g., unobserved genetic, hormonal, and biochemical environmental factors) [11]. Lifestyle choices including eating, smoking, exercise, alcohol consumption, sleep, weight (relative to height), and stress also can adversely affect health [11]. Obesity, a result of lifestyle outcomes, can adversely affect an individuals' health. The possible determinants of individuals' weight status linked to health are illustrated in the conceptual model shown in Figure 1. It demonstrates how weight and, in turn, health are influenced by a set of individual specific characteristics and aggregate level socioeconomic and environmental factors. Essentially, households produce good health by combining resources including limited time available for daily activities along with other goods such as medical care, diet, exercise, recreation, and housing shaped by socioeconomic, demographic, and environmental characteristics [10, 12]. The model emphasizes the fact that the context or the environment in which individuals live is important for health outcomes over and above individual factors. Moreover, the factors operating at the individual and contextual levels simultaneously interact and are synergistic to one another. With this background on the interplay among health, lifestyle, and the built environment in general, the following few sections explore some causes and consequences of obesity in detail.

\section{Trends in Food Consumption, Eating Habits, and Obesity}

It is well established that fast foods, which contain high levels of calories and saturated fats, have a positive impact on body weight $[13,14]$. In the USA, consumer spending at full-service and fast food restaurants is predicted to increase by $18 \%$ at full-service restaurants and by $6 \%$ at fast food restaurants between 2000 and 2020 [15].

A prime driver for fast food consumption is convenience. Both fast food restaurants and full-service restaurants can provide leisure for households, as households are freed from cooking, cleaning, and shopping $[16,17]$. And households that spend long hours working outside the home prefer consuming fast foods, if such meals are accessible within a reasonable location $[16,17]$. In addition, the age, race and ethnicity, and educational level of the head of the household, along with residential location, can influence the demand for food away from home $[13,18]$.

Benefiting from these growing trends in household lifestyles and eating habits, a wide array of food service firms, including full service restaurants, fast food establishments, hotels, retail stores, recreation places, bars, and vending machines, are competing for consumers' food away from home $(F A F H)$ expenditures [15]. The proliferation of fast food restaurants can also be seen as a trend known as the "channel-blurring" effect whereby gas stations and retail stores are hosting outlets for fast food giants [18].

Nonalcoholic beverages that are complementary in nature to fast food consumption may also be a contributory factor to current obesity trends [19, 20]. Consumers are offered a wide variation of choices among nonalcoholic beverages, and, simultaneously, there is a decreasing trend toward consumption of milk and increased consumption of other beverages. Beverage choices have important implications for intake of calories and therefore for obesity risk [1921]. Soft drinks are the major source of added sugars in American diets, contributing approximately a third of the added-sugar intake of Americans 2 years of age and older [22]. Increasing demand for sugar sweetened beverages (SSB) can be due to relatively low prices and their convenience [23].

\section{Relationship between Poverty and Obesity}

Poverty and poor health tend to go hand in hand [24, 25]. Many health disparities in the USA are linked to inequalities in education and income, having profound effects on diet structure, nutrition, and health [26]. Similar trends have also been found in other parts of the world [27]. Income and the macronutrient composition of diets are linked at the aggregate and most likely at the individual level. USA residents spent the lowest amount (less than 8\%) of disposable income on at-home food followed by Canada and the United Kingdom [26]. In higher-income nations, cost per unit of food energy is low such that those nations are associated with high-energy intakes. Accordingly, higher-income nations consume more added sugars and fats than those in lowincome nations. On the other hand, low-income consumers within rich nations consume lower-quality diets than higherincome consumers [26]. Evidence shows that the highest rates of obesity are among population groups with the highest poverty rates and the least education [28]. Moreover, an inverse relationship was observed between the energy density, mega joule per kilogram (MJ/kg), and energy cost $(\$ / M J)$, such that energy-dense foods composed of refined grains, added sugars, or fats become a low-cost option for the consumer [26]. Therefore, the selection of energy dense foods by food insecure, low-income consumers may represent a deliberate strategy to save money. Also, poverty and food insecurity are associated with lower food expenditures, low fruit and vegetable consumption, and lower-quality diets $[26,28]$. Food insecurity, which is defined as limited or uncertain availability of nutritionally acceptable safe foods, appears to be linked with obesity, with women and young girls who received food stamp benefits are also more likely to be obese [29]. In addition, communities with low socioeconomic status (SES) and high poverty are also associated with low levels of physical activity settings and are at risk of being overweight [30]. 


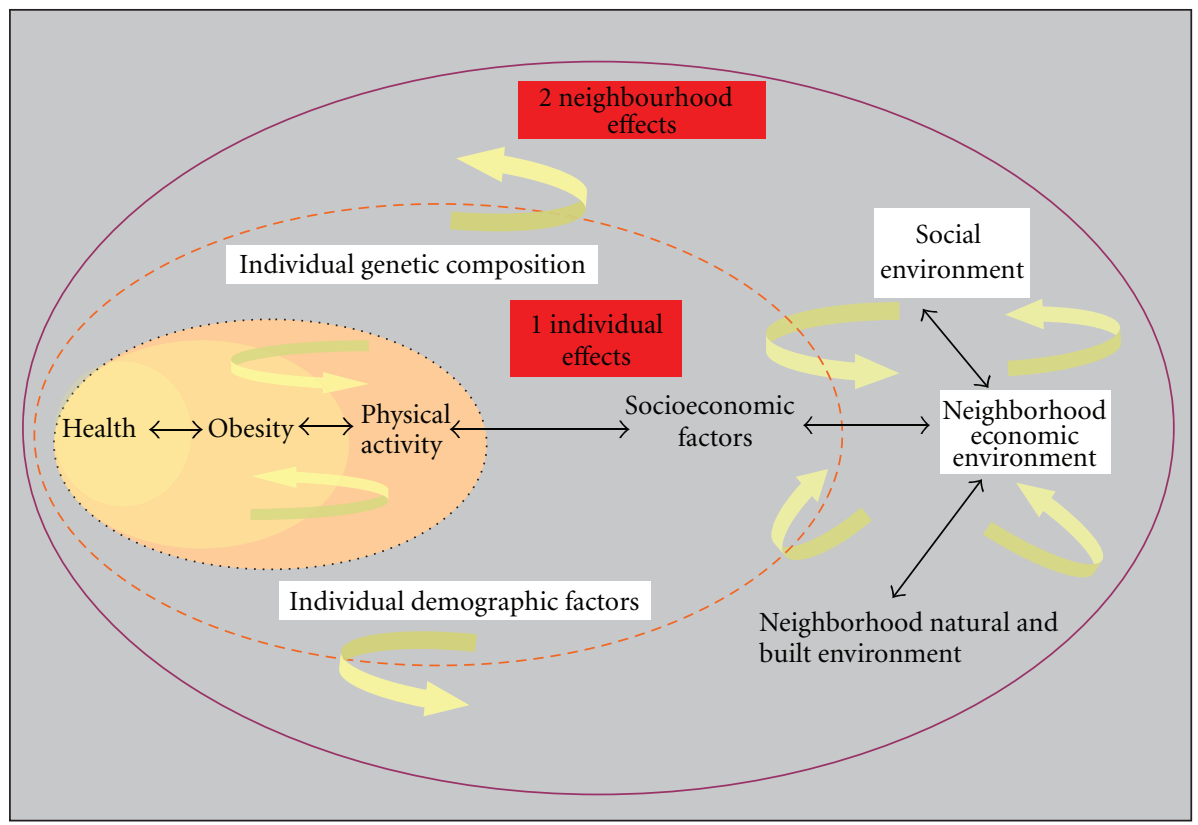

Figure 1: Conceptual model: possible interactions among health, obesity, and socioeconomic and environmental factors.

\section{Technological Change and Obesity}

One proposed explanation for the increase in obesity is longrun technological changes that have impacted food prices as well as the propensity to exercise. Even though the market price reflects a major component of the cost of the product, its full cost is comprised of other components such as time cost and information cost. For example, the full cost of a home-prepared meal includes not only the cost of ingredients bought at the store, but also the travel cost to the store and back, the cost of time spent preparing the food and information costs related to nutrition knowledge and cooking techniques. A change in any component of these costs will change the incentive for consuming that product, as well as its closely related alternatives [31]. Prices change over time due to a variety of reasons, including availability of resources, although, more recently, the prime mover of prices seems to be technology. Theoretically, better production and distribution technologies generate more and better goods, driving prices down. Food prices, whether at the store or at a restaurant, have been declining relative to prices of all other items between 1952 and 2003. The ratio of food prices to the price of all other goods has fallen by $12 \%$ [31]. Increase in food consumption prompted by the falling time cost devoted to food preparation is the major cause behind the surge in obesity since 1980 [31-33]. Technological innovationsincluding vacuum packing, improved preservatives, deep freezing, artificial flavors, and microwaves-have enabled food manufacturers to cook food centrally and ship it to consumers for rapid consumption. In 1965, cooking meals and associated cleaning up took over two hours per day, but in 1995 the same tasks took less than half the time. Although greater convenience, growing portion sizes, and increased accessibility of restaurant meals have been blamed for contributing to the rise in obesity, in economic terms, these are quality attributes that are valued by consumers [34].

Obesity is also believed to be accompanied by innovations that economize on time previously allocated to the nonmarket or household sector [34]. In the same period the number of full-service restaurants has risen by $35 \%$, according to the Census of Retail Trade [35]. An increasing trend of fast food consumption in favor of labor intensive preparation of food at home can be partly attributed to labor market developments since 1970. The real income of single earner households has declined from 1970 to 1993, and it was only 1\% higher in 1998 than 1970. Increases in hours of work and labor force participation, reduction in wage rates, and decline or modest increase in real incomes have stimulated the demand for inexpensive fast foods which are also high in caloric content. At the same time, the reduction in time available for active leisure has reduced the calories expended [35].

\section{Time Use, Leisure, Physical Inactivity, and Obesity}

Individuals make tradeoffs of time use decisions that affect daily life [35], and people are considered to divide their time between five categories of activities-sleep, leisure, occupation (paid work), transportation, and home production (unpaid work) - collectively referred to by the acronym SLOTH. Wages and unearned income are the most important economic determinants of labor supply of married women in the short run; thus, an increase in the market wage is expected to reduce work at home, while its effect on leisure and work in the market is indeterminate [35]. Increase in income may increase leisure, reduce work in the market, and leave work at home unchanged. At the same time, the wage penalty or the opportunity cost of time, time use decisions, 
and family health have taken on more importance today as more women participate in the labor force. The labor force participation rate of women with young children (under 6 years of age) increased from $39 \%$ in 1975 to $62 \%$ in 1996 [36]. Increased participation of women in the labor force has reduced time available for nonmarket household activities (i.e., home-based activities that are not paid for) and motivated people to consume relatively cheap highcaloric foods [35]. A substantial change in expenditures and time allocation has been observed in the area of leisure time and travel/transportation. Since 1965, overall leisure time has increased by greater than 4 hours per week, time spent at paid work and on productive activities at home (cooking, cleaning, repairing things, and childcare) has diminished, transportation time has increased, and time for personal care (taking showers, getting dressed, or eating) has remained the same. Along with these developments, many individuals tend to spend more of their leisure time engaged in sedentary activities at the expense of physical activities, such that increasing weight is accompanied by increased leisure time [37]. Evidence suggests that children who engage in less vigorous physical activity and more sedentary activities such as television viewing tend to be more overweight [38]. In contrast, recent evidence shows that television advertising rather than viewing per se is associated with obesity [39]. This, perhaps, is due both to the type of product and the suggestive nature of the ads themselves.

In 2001, less than half of US adults achieved recommended levels of physical activity, and most of those who walked for exercise did not walk long enough, often enough, or briskly enough to obtain health benefits [30]. Individuals with higher incomes or education were more likely to engage in healthy behaviors including eating a healthier diet, reducing television viewing, and increased participation of active sports $[37,40]$. In addition, recreational and physical activities are also shaped by the contextual and the compositional factors of the environment where individuals live.

\section{Built Environment and Obesity}

There has been a growing concern that urban sprawl and the structure of the built environment have an impact on the escalation of noncontagious health disorders [41-43]. While sprawl is a somewhat imprecise and difficult to measure phenomenon, it is often characterized by low-density urban development that consumes land faster than the growth of the population. More specifically sprawl environments are characterized by (1) a population widely dispersed in low-density residential development; (2) rigid separation of homes, shops, and workplaces; (3) a lack of distinct activity centers, such as strong and thriving downtowns or suburban town centers; and (4) a network of roads marked by large block size and poor access from one place to another $[44,45]$. This redistribution of population to suburbs and away from central cities and rural areas has given rise to undesirable impacts on metropolitan residents and communities [46]. These impacts include the destruction of open space and farmland, increased automobile congestion and pollution, the geographic isolation of low-income and minority residents, and a mismatch between the location of jobs and the residences of workers, especially, low-skilled, low-income workers. These developments are important, because transportation, which is a key factor of everyday life, could also be a decisive factor of changes in physical activity as small shifts in travel modes noticeably alter energy expenditure. While time spent on transportation has increased, suburbanization, street design, and land use patterns can reduce the amount of physical activity that can be achieved through transportation $[28,37,44]$. The influence of transportation on energy expenditure is mainly affected through the built environment in which the cities and transportation corridors are planned and developed [47].

Evidence also suggests that residents of sprawling neighborhoods were also more likely to walk less during leisure time, weigh more, and have a greater prevalence of hypertension than residents of compact counties [45, 48]. Moreover, urban sprawl is positively correlated with other undesirable social outcomes including overall traffic fatality rate, as well as with an array of transportation outcomes (e.g., percentage of residents walking or taking public transit to work, average vehicle ownership, and vehicle miles traveled per capita) and environmental outcomes (e.g., ground-level ozone levels) $[45,48]$. The most compact counties (i.e., those with the highest population density and street accessibility and, therefore, the higher index value) had lower traffic fatality rates; in fact, for every $1 \%$ increase in the index, the traffic fatality rate decreased by $1.49 \%$. These adverse outcomes may also lead to increased reliance on automobile transportation and decreased ability to walk to destinations, decreased neighborhood cohesion, and environmental degradation (e.g., greenhouse gas emissions and destruction of open space) $[45,48]$.

One US study showed that, after controlling for socioeconomic and demographic factors, for each one point rise in the urban sprawl index (0-100 scale), the risk of being overweight increased by $0.2 \%$ and the risk of being obese increased by $0.5 \%$ [49]. Urban sprawl may reduce the time available for physical activity because parks or fitness facilities are more distant. It may also affect diets by increasing the distance to supermarkets or by the increased cost of nutritious foods caused by the conversion of farmland to urban areas [45]. Thus, there is an increasing consensus that the built environment may play a major role in controlling weight by shaping food access and availability Though the relationship between different types of eating places and dietary consumption has not been well examined, availability, type, and distribution of restaurants and the diffusion of food advertising represent other means by which the environment affects weight imbalances [50]. It was shown that establishment of "supercenter" retail grocery stores tends to create food deserts for the rural population [50]. When a supercenter is opened in nonmetropolitan areas, it draws customers from a wide radius such that existing small retailers in these areas go out of business due to loss of customers. This places low-income earners at a disadvantage when it comes to finding low cost grocery stores [50]. On the other hand, there is a geographic correlation between the exposure of low-income neighborhoods to fast food 
restaurants $[14,16,17]$. The predominantly black neighborhoods in the USA have 2.4 fast food restaurants per square mile compared to 1.5 restaurants in predominantly whiteneighborhoods [51]. A study from Australia showed that residents of low-income neighborhoods have 2.5 times more exposure to fast food restaurants than those living in affluent neighborhoods [52].

There is increasing evidence that mixed-use environments are meant to create more active, healthier, and livable communities [53]. Another US study pointed out that the likelihood of obesity apparently declined with an increase in mixed land use but rose with time spent per day in a car. While each $25 \%$ increase in mixed land use lowered the risk of being obese by $12 \%$, each additional hour spent in a car raised the likelihood of obesity by $6 \%$, while each additional kilometer walked per day was associated with a $5 \%$ reduction in the likelihood of obesity [54]. It was also found that increasing recreation opportunities had the potential to decrease health care expenditures and rates of obesity through increasing rates of physical activity [55].

In addition, neighborhood social capital contributes to better health through the diffusion of knowledge about health promotion, maintenance of healthy behavioral norms through informal social control, and access to local services and amenities [56]. Findings also suggest that lifestyle behaviours are culturally driven, so that individual self-image and social interactions could play a role in determining one's body weight [57]. In addition to differences among individuals, differences among places, in particularly ethnic composition, may be relevant to weight and health policy promotional efforts $[58,59]$.

\section{Obesity: A Result of Market Failure?}

Obesity could also be a result of market failure [28, 60]. Like environmental pollution, it imposes an external cost to society so that public intervention to control obesity is justified. In order to reduce the consumption of unhealthy foods, it has been suggested that foods high in calories, fat, or sugar be taxed and that healthy foods such as fruits and vegetables be subsidized $[28,61]$. A steep tax would probably reduce consumption of taxed foods and could be used to generate funding to subsidize healthful foods; although it was found that fruit and vegetable subsidies were more likely to increase sales, there were mixed opinions on the feasibility and desirability of a steep "junk food" tax [62]. A small tax was found to likely be more politically feasible and still could generate significant revenues to support health measures. Previous studies have suggested that economic instruments such as taxes are a means of changing undesirable behaviors such as alcohol and tobacco consumption [63]. Two community-based intervention studies in the USA showed that price reductions resulted in a fourfold increase in fresh fruit sales and a twofold increase in baby carrot sales [64]. This study also concluded that price reduction was an effective strategy to increase the purchase of more healthful foods in community-based settings such as work sites and schools.
Many studies have dealt with the implications of taxes on energy dense snack foods and soft drinks [62, 65-67]. In the US, there are about 19 states that levy taxes on soft drinks, candy, chewing gum, or snack foods (potato chips, pretzels, and others) [62]. These taxes could be levied at the wholesale or retail level in terms of a fixed tax per volume of product (i.e., excise tax) or as a percentage of sales price (sales tax). However, a relatively small ad valorem tax would not immediately change a consumer's diet, thus having little effect on the quality of one's diet or health outcomes. Nonetheless, substantial revenue generated from these smalls taxes could be used in educational programs leading to healthier food choices $[23,62,65]$. Even though taxing snacks and fast food has been advocated frequently, it is difficult to confirm the economic efficacy of such taxes without a clear understanding of the influence of tax on weight issues $[23,59]$.

On the other hand, the change in consumption of fruits and vegetables could be induced by modest subsidies in retail prices [68]. Empirical simulations showed that, on average, the present value of the cost per statistical life saved for a $1 \%$ fruit and vegetable subsidy is $\$ 1.29$ million. Since fat taxes are regressive, tax incidence would be felt hardest by low-income families. In contrast to fat taxes, subsidy programs would likely be progressive as the largest benefits would go to low-income earners. But these subsidy programs have to be funded by taxpayers so it is necessary to further investigate the societal welfare impacts in general, and whether or not such policies would be cost-effective in achieving health improvement [68]. Developing economies resort to discriminatory excise taxes as stopgap measures to solve short-term economic problems [69].

The evidence between drinking alcoholic beverages and body weight has been inconsistent. Recent evidence suggests that infrequent alcohol-related overeating could lead to weight gain over time [70]. However, taxing alcoholic beverages to reduce the social cost of alcohol consumption has been a long-debated public policy issue. It has been argued that public health costs and other external costs associated with alcoholic beverages are so significant that imposing a substantial excise tax on those beverages is justified [71].

Even though taxes on cigarettes and alcohol consumption produce economic benefits by reducing various external costs, these taxes can also create an economic cost, for example, by tempting people to consume less of the desired commodity and more of other commodities than they otherwise would. The marginal excess burden (MEB) of a tax refers to the welfare loss (or gain), net of any external benefits caused by the increase in the tax necessary to raise an extra dollar of revenue for the government [72]. Information on the MEB of different taxes would help determine the economic case for tax reforms such as the effect of cutting one tax at the expense of raising another tax, holding total tax revenue constant. Even though the usage of economic incentives to correct externalities of such health disorders is economically justifiable, in reality, their applicability depends on the tradeoff between the marginal excess burden of economic incentives (e.g., taxes) in controlling such health issues and the marginal external cost of such health issues to society. If marginal external costs of obesity are greater than 


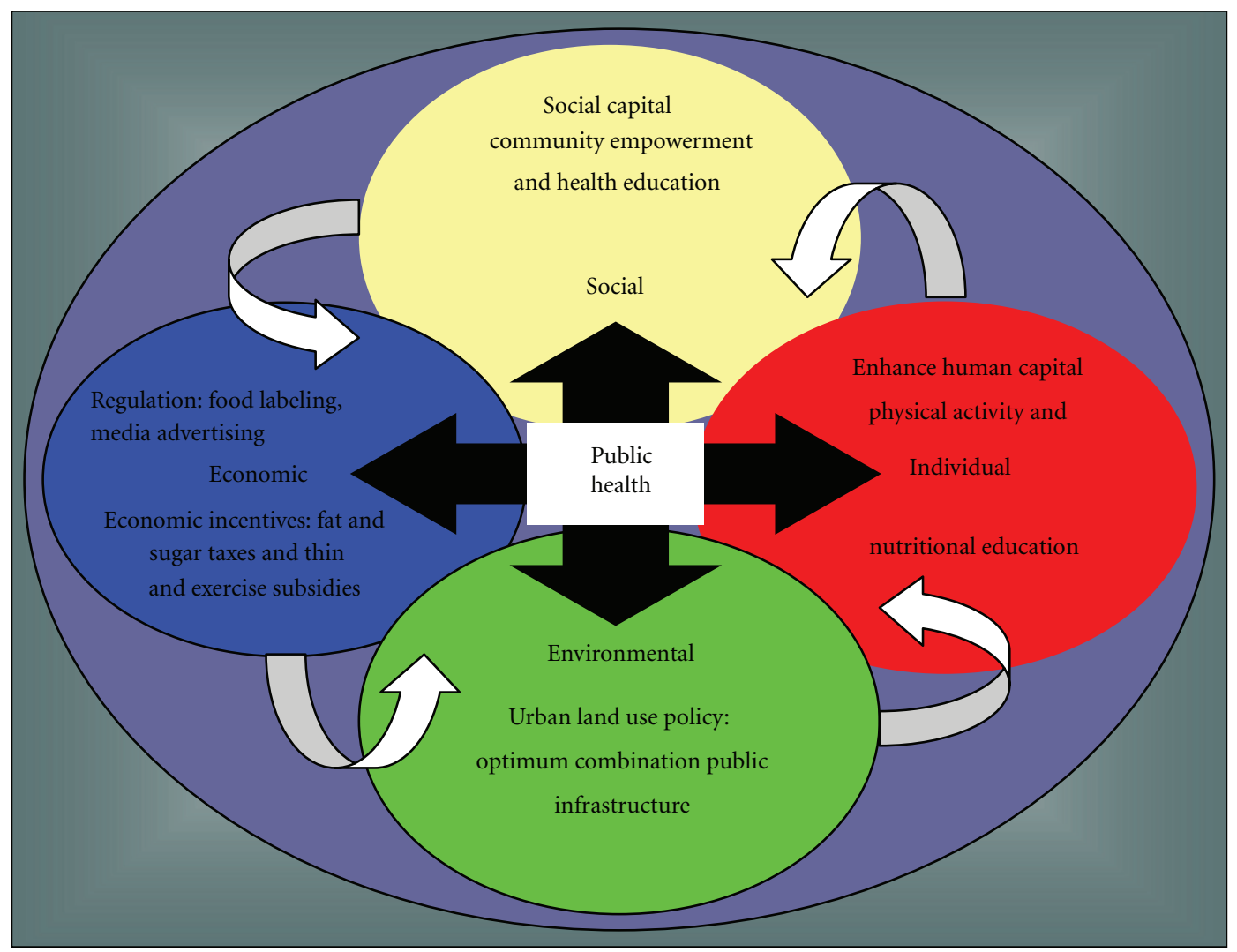

FIGURE 2: Individual, socioeconomic, and ecological model (ISEEM) for obesity prevention and health promotion.

the marginal excess burden of taxes to control it, the use of taxes would create a Pareto welfare improvement in society (i.e., making some one better off without making any one else worse off). Therefore, the use of economic incentives such as taxes to control obesity becomes an important question worthy of research $[23,73,74]$.

\section{Implications for Heath Promotion: ISEEM Framework}

Noticeably, the growing trend of obesity can be attributed to a combination of economic, social, cultural, environmental, and political factors in addition to genetic factors. Although the unobserved genetic influences are difficult to manage, the impact of the multifactorial obesity problem on health requires a system intervention approach involving changes in attitudes, increasing the role and value of local food systems, fostering economic development though less caloric value added products, and providing built and natural environments for recreational opportunities. A possible conceptual framework for multidimensional system intervention is illustrated in Figure 2. The four circles depicted as individual, social, environmental, and economic are core elements of the ISEEM intervention to promote health and curb obesity. These core elements should be integral parts of the modern day health promotion. Any policy interventions, targeted on one element has synergistic impacts on the other. Careful coordination of these elements yields far reaching benefits for socioeconomic wellbeing. This framework suggests that a dynamic and integrated individual, social, economic and environmental model (ISEEM) could work well for obesity prevention. Interventions at each segment have their own merits/demerits which are directly or indirectly interrelated to each other. A combination (or portfolio) of ISSEM strategies is essential to address obesity, although some are considered to create an externality to society through increased health care costs, which are to be borne largely by taxpayers.

The ISEEM framework suggests that obesity prevention does not have just one stand-alone intervention or a solution. It needs contributions from an individual combined with aggregate level social, economic, and environmental interventions. In effect, the intervention in one segment feeds into the other. This can be achieved through a proper institutional framework in place to facilitate interactions between relevant stakeholders to use limited obesity prevention resources wisely.

Ad hoc dumping of much needed financial resources may create unintended complexities rather than addressing the needs of the issue. Thus, a concerted effort and coordination from the federal state and local governments for obesity prevention is essential and justified, if the ISEEM framework is to be feasible. As has been pointed out, all state and local health departments have a unique responsibility to address health issues including obesity. By coordinating cross-agency conversations and policymaking, health departments can insert health concerns into a vast range of policymaking 


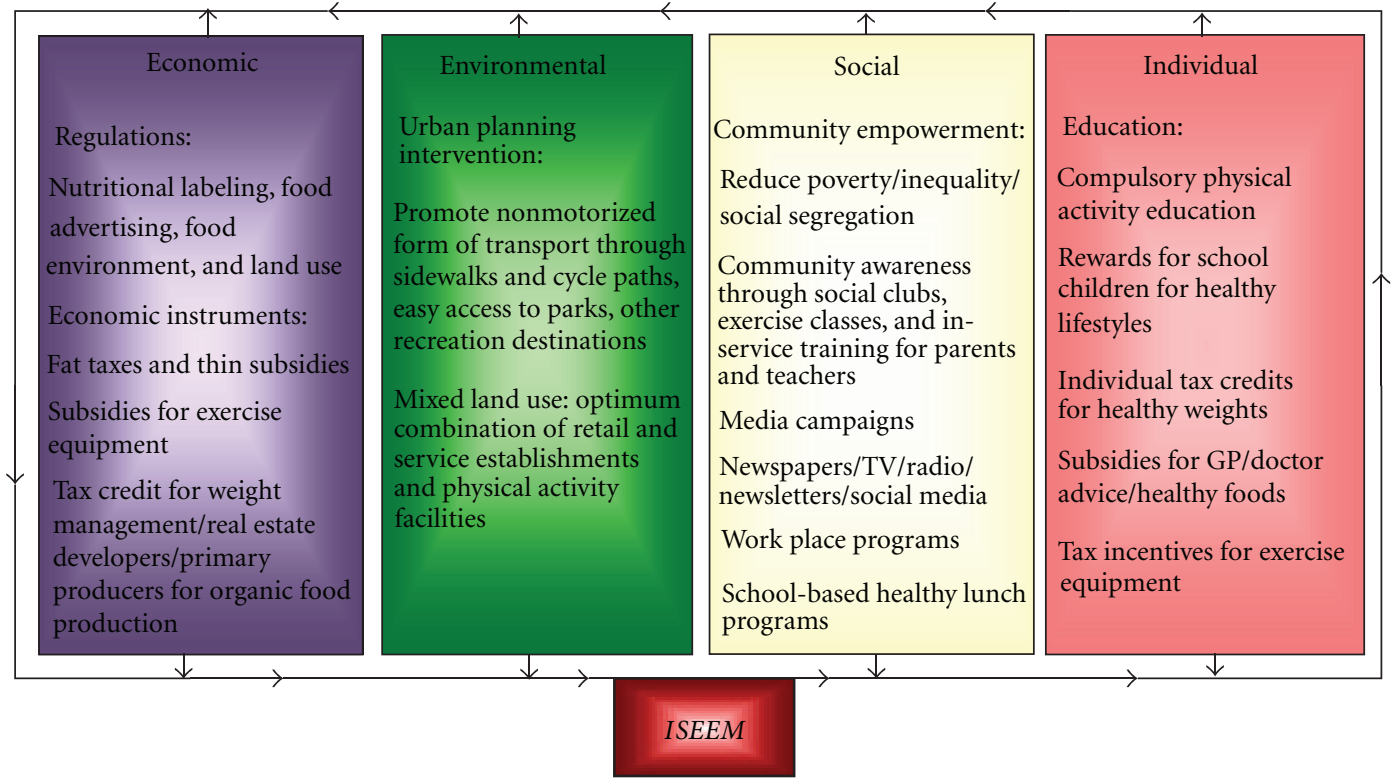

FIgURE 3: A portfolio of choices for obesity prevention.

activities within their jurisdictions. This can bring health issues from the traditional health sectors into other government entities, thereby influencing transportation, housing, environment, education, and fiscal policies $[8,9,28,53,75]$. However, like many other public policy programs, any policy for obesity prevention needs to be economically efficient, socially acceptable, easy to implement, provide flexibility for unforeseeable events, be politically feasible, and yield dynamic incentives [76].

The use of command and control approaches to correct inadvertent lifestyle outcomes may not be acceptable morally and socially. Taxing the individual directly may not be practical and may also be unjustifiable, as obesity is not only associated with hereditary issues but is partly the unintended consequence of current economic activities. In lieu of regulatory approaches, the use of economic instruments (i.e., tax and subsidies) may be more efficient, flexible, and equitable than command and control approaches. However, in terms of political feasibility, a tax could be the least amenable policy intervention. Given the complexity of the present obesity issue, it may urgently need a combination of regulatory and economic instruments to control behavioral health problems. Similar to taxes on tobacco and alcohol, imposing taxes on fast foods, food away from home, snacks, and promotional food advertisements would be timely. However, it should also be noted that implementing taxes may create other market distortions including an excess burden on the economy. If the external cost of obesity is greater than the excess burden of imposed taxes, a tax on fatty foods may be justifiable. On the other hand in kind subsidies for healthy foods such as fruit vegetables, tax credits for weight management, and subsidies for exercise equipment are some other fiscal policy instruments available for obesity control. Even though the use of economic instruments for obesity prevention needs further research, they seem to be the most flexible policy measures available for unforeseeable economic and political downturns. In fact, the effect on regulatory measures and economic instruments reflects on the social natural and built environments and, in turn, on individuals.

Together with economic incentives, careful planning of mixed natural and built environments that have close access to recreational facilities and destinations may have profound effects on improving physical activity such as walking and cycling and thereby reducing obesity. Even though new urbanist planning policies have led to a growing number of studies to suggest social-ecological approaches to understand health-lifestyle issues, one of the major challenges of such policy is residential "self-selection." Residential self-selection implies that residents who value recreational benefits such as walking gravitate to predetermined residential environments or vice versa.

Regardless of the validity of such hypotheses, it may be helpful in improving physical activity and subsequent reductions in obesity at least on the part of the population that likes walking. In addition to these favorable health outcomes, ecological interventions are believed to be a remedy for other public policy goals including reduced crimes, reduced air pollution, and increased social cohesion. In any case, it is worthwhile to further investigate the efficacy of such interventions for health gains before implementing large-scale urban design interventions for obesity prevention.

However, changes in economic and neighborhood built environments have profound effects on both society and individuals. Because poverty and food insecurity are also possible contributory factors, undoubtedly, community empowerment programs especially for disadvantaged communities should be in place without further delay. Previous studies have consistently indicated that community outreach educational programs, indeed, have a powerful impact both 
on socioeconomic lifestyles (such as dietary patterns and recreational activities) as well as on health $[28,44]$. At the same time, formal and informal education can be a remedy for other pressing socioeconomic problems such as poverty and unemployment. Education is one of the key determinants of human capital, not only providing an economic return, but also increasing employment rates and earnings and improving health, well-being, parenting, and social cohesion. Therefore, interventions which enhance educational attainment could play a vital role in addressing obesity especially in vulnerable, low-income populations. Unfortunately, childhood overweight and obesity is also a poignant part of the current obesity epidemic. An intervention tailored to young individuals is important and timely. Establishment of a reward system for young school children for maintaining healthier weight limits, tax credits to households or for schools, healthy school lunch menus, and reward systems in the work place for maintaining healthier lifestyles could be examples of other community intervention strategies to control obesity. As youngsters represent the future of communities, allocation of resources tailored at school-based physical activity and educational programs will ensure that such interventions are sustainable.

It is also important to note that the ISEEM framework does not necessarily rule out small-scale approaches to obesity prevention. Interventions aimed at helping people make conscious small changes in lifestyle behaviors are also important. Small-scale interventions with efforts for gradual eliminating of some environmental factors contributing to excessive energy intake are complementary to the success of the ISEEM framework. Such initiatives would undoubtedly benefit from the educational and social marketing campaigns developed with governmental input and support [77].

\section{Conclusions}

A single intervention alone may not be viable and economically efficient for multifaceted, modern day health issues like obesity. The use of an ISEEM framework involving an effective combination of strategies including economic incentives and regulations, community interventions, and better land use planning is proposed to control the current obesity epidemic. Possible strategies to accomplish this are presented in Figure 3. Since interventions in each segment tend to be synergistic, the use of the proposed ISEEM framework targeted to specific circumstances of individual communities and localities offers a promising and a sustainable approach to combat the "wicked problem" of obesity.

\section{Acknowledgments}

The views, opinions, and conclusions expressed in this paper are solely the responsibility of the authors and do not necessarily represent the official view of the respective institutes. The financial support from USDA Hatch funds and a Canaan Valley Institute (CVI) grant is gratefully acknowledged. The authors also acknowledge helpful comments and suggestions from Cheryl Brown and Tim Phipps of the Davis College of Agriculture, Forestry and Consumer Sciences at
West Virginia University, and Tatiana Borisova, Food and Resource Economics Department, University of Florida. Also special thanks are to Billie Giles-Corti, former Director, the Centre for the Built Environment and Health (C_BEH) of the School of Population Health at the University of Western Australia for the assistance provided.

\section{References}

[1] WHO, Obesity and Overweight, Health Organization, Geneva, Switzerland, 2011.

[2] CDC, Obesity and Overweight: Data for the U.S, Centers for Disease Control and Prevention, Unites States Department of Health and Human Resources, Atlanta, Ga, USA, 2011.

[3] K. M. Flegal, M. D. Carroll, C. L. Ogden, and L. R. Curtin, "Prevalence and trends in obesity among US adults, 19992008," Journal of the American Medical Association, vol. 303, no. 3, pp. 235-241, 2010.

[4] R. J. Kuczmarski, C. L. Ogden, S. S. Guo et al., "CDC Growth Charts for the United States: methods and development," Vital and Health Statistics. Series 11, Data from the National Health Survey, no. 246, pp. 1-190, 2002.

[5] L. E. Egede and D. Zheng, "Modifiable cardiovascular risk factors in adults with diabetes: prevalence and missed opportunities for physician counseling," Archives of Internal Medicine, vol. 162 , no. 4, pp. 427-433, 2002.

[6] G. Wang, Z. J. Zheng, G. Heath, C. Macera, M. Pratt, and D. Buchner, "Economic burden of cardiovascular disease associated with excess body weight in U.S. Adults," American Journal of Preventive Medicine, vol. 23, no. 1, pp. 1-6, 2002.

[7] J. F. Bell, F. J. Zimmerman, D. E. Arterburn, and M. L. MacIejewski, "Health-care expenditures of overweight and obese males and females in the medical expenditures panel survey by age cohort," Obesity, vol. 19, no. 1, pp. 228-232, 2011.

[8] V. Niehoff, "Childhood obesity: a call to action," Bariatric Nursing and Surgical Patient Care, vol. 4, no. 1, pp. 17-23, 2009.

[9] WHTFCO Solving the problem of childhood obesity within a generation, White House Task Force on Childhood Obesity, Washington, DC, USA, 2010.

[10] M. Grossman, "On the concept of Health capital and the demand for health," The Journal of Political Economy, vol. 80, pp. 223-253, 1972.

[11] N. B. Belloc and L. Breslow, "Relationship of physical health status and health practices," Preventive Medicine, vol. 1, no. 3, pp. 409-421, 1972.

[12] R. F. Muth, "Household production and consumer demand functions," Econometrica, vol. 34, pp. 699-708, 1966.

[13] B. Anderson, S. Lyon-call, C. Fussman, G. Imes, and A. Rafferty, "Fast-food consumption and obesity among Michigan adults," Preventive Chronic Diseases, vol. 8, p. A71, 2011.

[14] L. V. Moore, A. V. Diez Roux, J. A. Nettleton, D. R. Jacobs, and M. Franco, "Fast-Food consumption, diet quality, and neighborhood exposure to fast food," American Journal of Epidemiology, vol. 170, no. 1, pp. 29-36, 2009.

[15] H. Stewart, N. Blisard, S. Bhuyan, and R. Nayga, The Demand for Food Away From Home Full-Service or Fast Food?, Economic Research Service, USDA, 2004.

[16] N. K. Mehta and V. W. Chang, "Weight status and restaurantavailability. A multilevel analysis," American Journal of Preventive Medicine, vol. 34, no. 2, pp. 127-133, 2008.

[17] S. Y. Chou, M. Grossman, and H. Saffer, "An economic analysis of adult obesity: results from the Behavioral Risk Factor 
Surveillance System," Journal of Health Economics, vol. 23, no. 3, pp. 565-587, 2004.

[18] L. M. Powell, S. Slater, D. Mirtcheva, Y. Bao, and F. J. Chaloupka, "Food store availability and neighborhood characteristics in the United States," Preventive Medicine, vol. 44, no. 3, pp. 189-195, 2007.

[19] S. T. Yen and B. H. Lin, "Beverage consumption among US children and adolescents: full-information and quasi maximum-likelihood estimation of a censored system," European Review of Agricultural Economics, vol. 29, no. 1, pp. 85-103, 2002.

[20] O. Capps, A. Clauson, J. Guthrie, G. Pittman, and M. Stockton, Contributions of Nonalcoholic Beverages to the U.S. Diet, Economic Research Service, USDA, 2005.

[21] V. S. Malik, M. B. Schulze, and F. B. Hu, "Intake of sugarsweetened beverages and weight gain: a systematic review," American Journal of Clinical Nutrition, vol. 84, no. 2, pp. 274 288,2006

[22] J. F. Guthrie and J. F. Morton, "Food sources of added sweeteners in the diets of Americans," Journal of the American Dietetic Association, vol. 100, no. 1, pp. 43-51, 2000.

[23] L. M. Powell and F. J. Chaloupka, "Food prices and obesity: evidence and policy implications for taxes and subsidies," Milbank Quarterly, vol. 87, no. 1, pp. 229-257, 2009.

[24] R. Knutson, J. Penn, and W. Boehm, Agricultural and Food Policy, Prentice Hall, New Jersey, NJ, USA, 1995.

[25] R. Wilkinson, The Impact of Inequality, Routledge, New York, NY, USA, 2006.

[26] A. Drewnowski and S. E. Specter, "Poverty and obesity: the role of energy density and energy costs," American Journal of Clinical Nutrition, vol. 79, no. 1, pp. 6-16, 2004.

[27] M. L. Loureiro and R. M. Nayga, "International dimensions of obesity and overweight related problems: an economics perspective," American Journal of Agricultural Economics, vol. 87, no. 5, pp. 1147-1153, 2005.

[28] A. Amarasinghe, G. D'Souza, C. Brown, H. Oh, and T. Borisova, "The influence of socioeconomic and environmental determinants on health and obesity: a West Virginia case study," International Journal of Environmental Research and Public Health, vol. 6, no. 8, pp. 2271-2287, 2009.

[29] M. S. Townsend, J. Peerson, B. Love, C. Achterberg, and S. P. Murphy, "Food insecurity is positively related to overweight in women," Journal of Nutrition, vol. 131, no. 6, pp. 1738-1745, 2001.

[30] L. Powell, S. Slater, and F. Chaloupka, "The relationship between community physical activity settings and race, ethnicity and socioeconomic status," Evidence-Based Preventive Medicine, vol. 1, pp. 135-144, 2004.

[31] J. Variyam, The Price is Right :Economics and Rising Obesity, Amber Waves, 2005.

[32] D. Lakdawalla and T. Philipson, "The growth of obesity and technological change," Economics and Human Biology, vol. 7, no. 3, pp. 283-293, 2009.

[33] T. J. Philipson and R. A. Posner, "The long-run growth in obesity as a function of technological change," Perspectives in Biology and Medicine, vol. 46, no. 3, pp. S87-S107, 2003.

[34] D. M. Cutler, E. L. Glaeser, and J. M. Shapiro, "Why have Americans become more obese?" Journal of Economic Perspectives, vol. 17, no. 3, pp. 93-118, 2003.

[35] Gronau, "Leisure, home production, and work: the theory of the allocation of time revisited," The Journal of Political Economy, vol. 85, pp. 1099-1124, 1977.

[36] M. A. Lee and M. Mather, "U.S. Labor force trends," Population Bulletin, vol. 63, no. 2, pp. 3-16, 2008.
[37] R. Sturm, "The economics of physical activity: societal trends and rationales for interventions," American Journal of Preventive Medicine, vol. 27, no. 3, pp. 126-135, 2004.

[38] J. A. Mendoza, F. J. Zimmerman, and D. A. Christakis, "Television viewing, computer use, obesity, and adiposity in US preschool children," International Journal of Behavioral Nutrition and Physical Activity, vol. 4, article 44, 2007.

[39] F. J. Zimmerman and J. F. Bell, "Associations of television content type and obesity in children," American Journal of Public Health, vol. 100, no. 2, pp. 334-340, 2010.

[40] L. Mancino, B. Lin, and N. Ballinger, The role of economics in eating choices and weight outcomes. Economic Research Service, USDA, Agriculture Information Bulletin Number 2004.

[41] J. Feng, T. A. Glass, F. C. Curriero, W. F. Stewart, and B. S. Schwartz, "The built environment and obesity: a systematic review of the epidemiologic evidence," Health and Place, vol. 16, no. 2, pp. 175-190, 2010.

[42] M. A. Papas, A. J. Alberg, R. Ewing, K. J. Helzlsouer, T. L. Gary, and A. C. Klassen, “The built environment and obesity," Epidemiologic Reviews, vol. 29, no. 1, pp. 129-143, 2007.

[43] F. Li, P. A. Harmer, B. J. Cardinal et al., "Built environment, adiposity, and physical activity in adults aged 50-75," American Journal of Preventive Medicine, vol. 35, no. 1, pp. 38-46, 2008.

[44] R. Ewing, T. Schmid, R. Killingsworth, A. Zlot, and S. Raudenbush, "Relationship between urban sprawl and physical activity, obesity, and morbidity," American Journal of Health Promotion, vol. 18, no. 1, pp. 47-57, 2003.

[45] H. Frumkin, "Urban sprawl and public health," Public Health Reports, vol. 117, no. 3, pp. 201-217, 2002.

[46] J. Foster-Bey Sprawl, Smart Growth and Economic Opportunity, The Urban Institute, Metropolitan Housing Communities Policy Center, Program on Regional Economic Opportunities, Washington, DC, USA, 2002.

[47] M. Pratt, C. A. Macera, J. F. Sallis, M. O’Donnell, and L. D. Frank, "Economic interventions to promote physical activity: application of the SLOTH model," American Journal of Preventive Medicine, vol. 27, no. 3, pp. 136-145, 2004.

[48] L. Freeman, "The effects of sprawl on neighborhood social ties," Journal of the American Planning Association, vol. 67, no. 1, pp. 69-77, 2001.

[49] R. Lopez, "Urban sprawl and risk for being overweight or obese," American Journal of Public Health, vol. 94, no. 9, pp. 1574-1579, 2004.

[50] K. Morland, S. Wing, and A. D. Roux, "The contextual effect of the local food environment on residents' diets: the atherosclerosis risk in communities study," American Journal of Public Health, vol. 92, no. 11, pp. 1761-1767, 2002.

[51] J. P. Block, R. A. Scribner, and K. B. Desalvo, "Fast food, race/ ethnicity, and income: a geographic analysis," American Journal of Preventive Medicine, vol. 27, no. 3, pp. 211-217, 2004.

[52] D. D. Reidpath, C. Burns, J. Garrard, M. Mahoney, and M. Townsend, "An ecological study of the relationship between social and environmental determinants of obesity," Health and Place, vol. 8, no. 2, pp. 141-145, 2002.

[53] L. D. Frank and H. A. McKay, "Time to walk the talk: embracing the built environment to promote physical mobility," British Journal of Sports Medicine, vol. 44, no. 9, p. 615, 2010.

[54] L. D. Frank, M. A. Andresen, and T. L. Schmid, "Obesity relationships with community design, physical activity, and time spent in cars," American Journal of Preventive Medicine, vol. 27, no. 2, pp. 87-96, 2004.

[55] R. S. Rosenberger, Y. Sneh, T. T. Phipps, and R. Gurvitch, "A spatial analysis of linkages between health care expenditures, 
physical inactivity, obesity and recreation supply," Journal of Leisure Research, vol. 37, no. 2, pp. 216-235, 2005.

[56] D. Kim, S. V. Subramanian, S. L. Gortmaker, and I. Kawachi, "US state- and county-level social capital in relation to obesity and physical inactivity: a multilevel, multivariable analysis," Social Science and Medicine, vol. 63, no. 4, pp. 1045-1059, 2006.

[57] N. A. Christakis and J. H. Fowler, "The spread of obesity in a large social network over 32 years," The New England Journal of Medicine, vol. 357, no. 4, pp. 370-379, 2007.

[58] V. W. Chang, "Racial residential segregation and weight status among US adults," Social Science and Medicine, vol. 63, no. 5, pp. 1289-1303, 2006.

[59] J. M. Fletcher, D. E. Frisvold, and N. Tefft, "The effects of soft drink taxes on child and adolescent consumption and weight outcomes," Journal of Public Economics, vol. 94, no. 11-12, pp. 967-974, 2010.

[60] D. Miljkovic, W. Nganje, and H. de Chastenet, "Economic factors affecting the increase in obesity in the United States: differential response to price," Food Policy, vol. 33, no. 1, pp. 48-60, 2008.

[61] B. H. Lin, S. T. Yen, D. Dong, and D. M. Smallwood, "Economic incentives for dietary improvement among food stamp recipients," Contemporary Economic Policy, vol. 28, no. 4, pp. 524-536, 2010.

[62] M. F. Jacobson and K. D. Brownell, "Small taxes on soft drinks and snack foods to promote health," American Journal of Public Health, vol. 90, no. 6, pp. 854-857, 2000.

[63] D. Coate and M. Grossman, "Effects of alcoholic beverage prices and legal drinking ages on youth alcohol use," Journal of Law and Economics, vol. 31, no. 1, pp. 145-171, 1988.

[64] M. Grossman, "Health benefits of increases in alcohol and cigarette taxes," British Journal of Addiction, vol. 84, no. 10, pp. 1193-1204, 1989.

[65] E. A. Finkelstein, C. Zhen, J. Nonnemaker, and J. E. Todd, "Impact of targeted beverage taxes on higher- and lowerincome households," Archives of Internal Medicine, vol. 170, no. 22, pp. 2028-2034, 2010.

[66] R. Sturm, L. M. Powell, J. F. Chriqui, and F. J. Chaloupka, "Soda taxes, soft drink consumption, and children's body mass index," Health Affairs, vol. 29, no. 5, pp. 1052-1058, 2010.

[67] C. Zhen, M. K. Wohlgenant, S. Karns, and P. Kaufman, "Habit formation and demand for sugar-sweetened beverages," American Journal of Agricultural Economics, vol. 93, no. 1, pp. 175193, 2011.

[68] S. Cash, D. Sunding, and D. Zilberman, "Fat taxes and thing subsidies: prices, diet and health outcomes," in Annual Meeting of the American Agricultural Economics Association, Denver, Colo, USA, 2004,.

[69] R. Bahl, "Why levy discriminatory excises on soft drinks," in of International Studies Program, Policy Studies, Georgia State University, 1998.

[70] P. M. Suter, "Is alcohol consumption a risk factor for weight gain and obesity?" Critical Reviews in Clinical Laboratory Sciences, vol. 42, no. 3, pp. 197-227, 2005.

[71] F. Pogue and L. Sgontz, "Taxing to control social costs: the case of alcohol," The American Economic Review, vol. 79, pp. 235243, 1989 .

[72] I. Parry, Comparing the Marginal Excess Burden of Labor, Petrol, Cigarette, and Alcohol Taxes: An Application to the United Kingdom, Resource for the Future, Washington, DC, USA, 2001.

[73] J. Block and C. Walter, "Can taxing sugary soda influence consumption and avoid unanticipated consequences?" Choices, vol. 26, 2011.
[74] J. Fletcher, "Soda Taxes and Substitution effects: will obesity be affected ?" Choices, vol. 26, 2011.

[75] A. K. Amarasinghe, "Cost-effectiveness implications of GP intervention to promote physical activity: evidence from Perth, Australia," Cost Effectiveness and Resource Allocation, vol. 8, article 10, 2010.

[76] P. Bohm and C. S. Russell, "Comparative analysis of alternative policy instruments," Handbook of Natural Resource and Energy Economics, pp. 395-460, 1985.

[77] J. O. Hill, "Can a small-changes approach help address the obesity epidemic? A report of the joint task force of the american society for nutrition, institute of food technologists, and international food information council," American Journal of Clinical Nutrition, vol. 89, no. 2, pp. 477-484, 2009. 


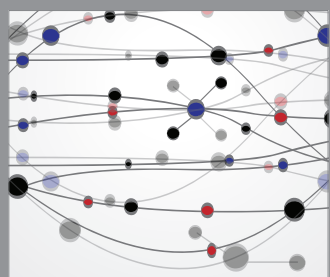

The Scientific World Journal
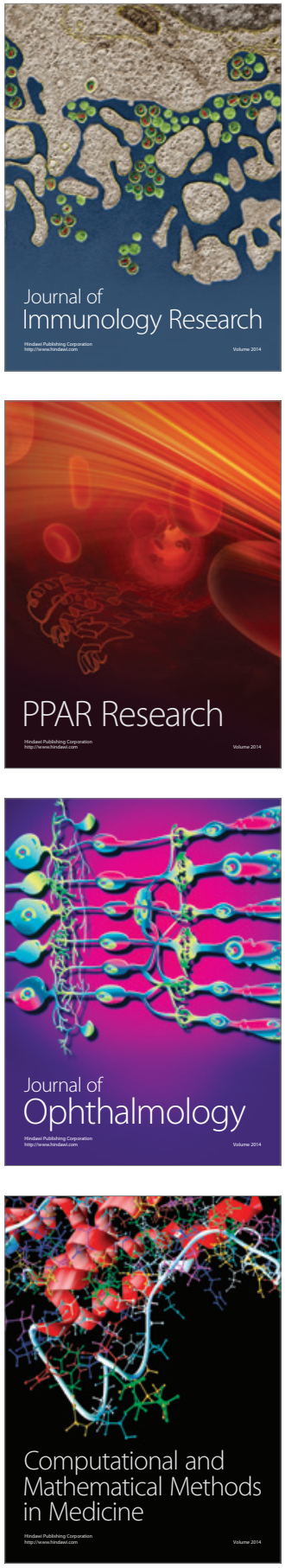

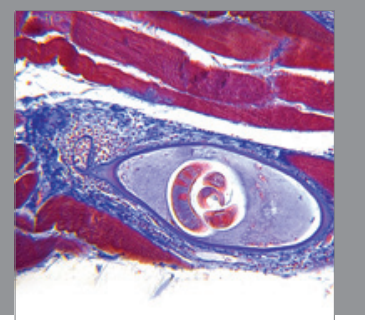

Gastroenterology

Research and Practice
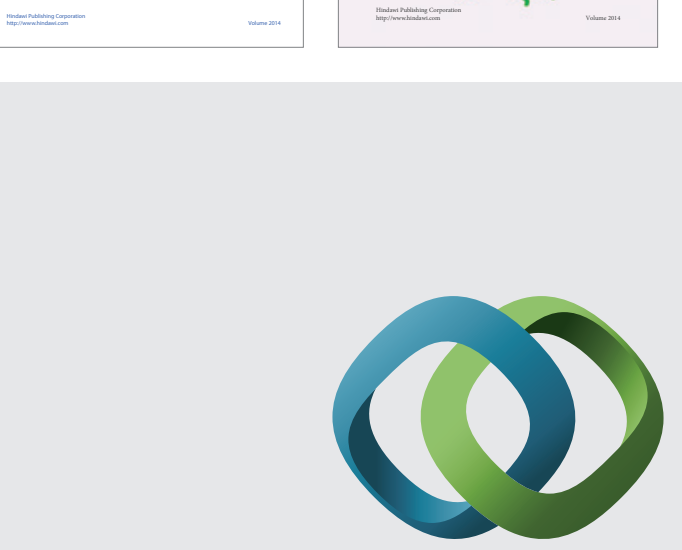

\section{Hindawi}

Submit your manuscripts at

http://www.hindawi.com
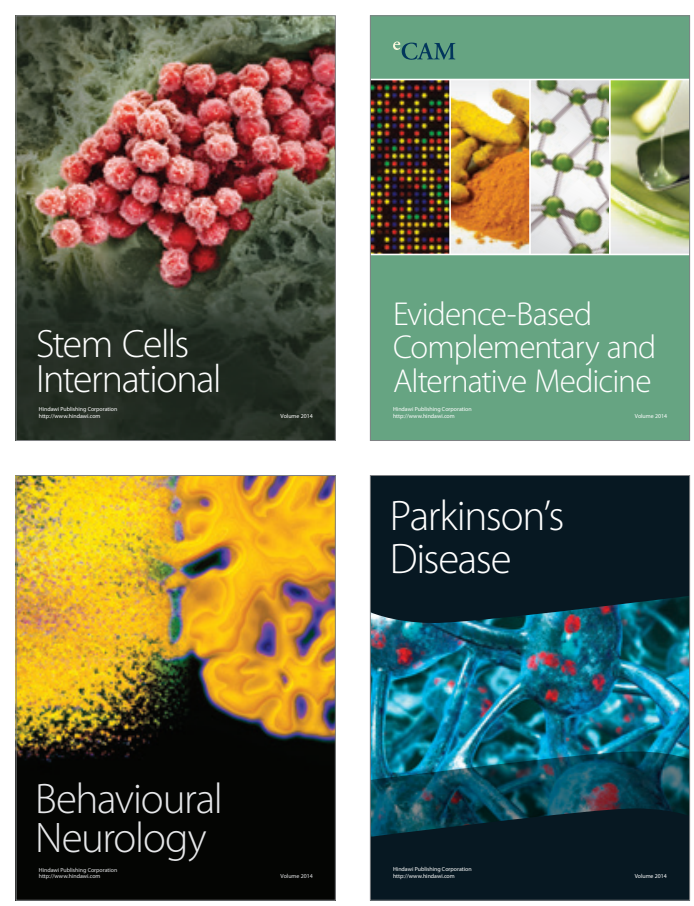

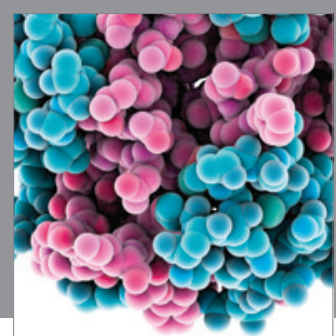

Journal of
Diabetes Research

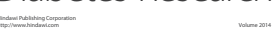

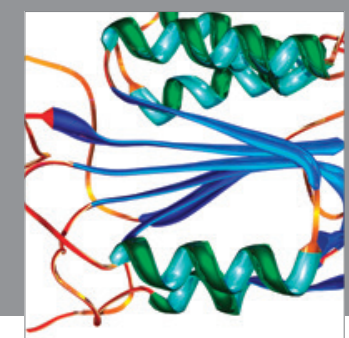

Disease Markers
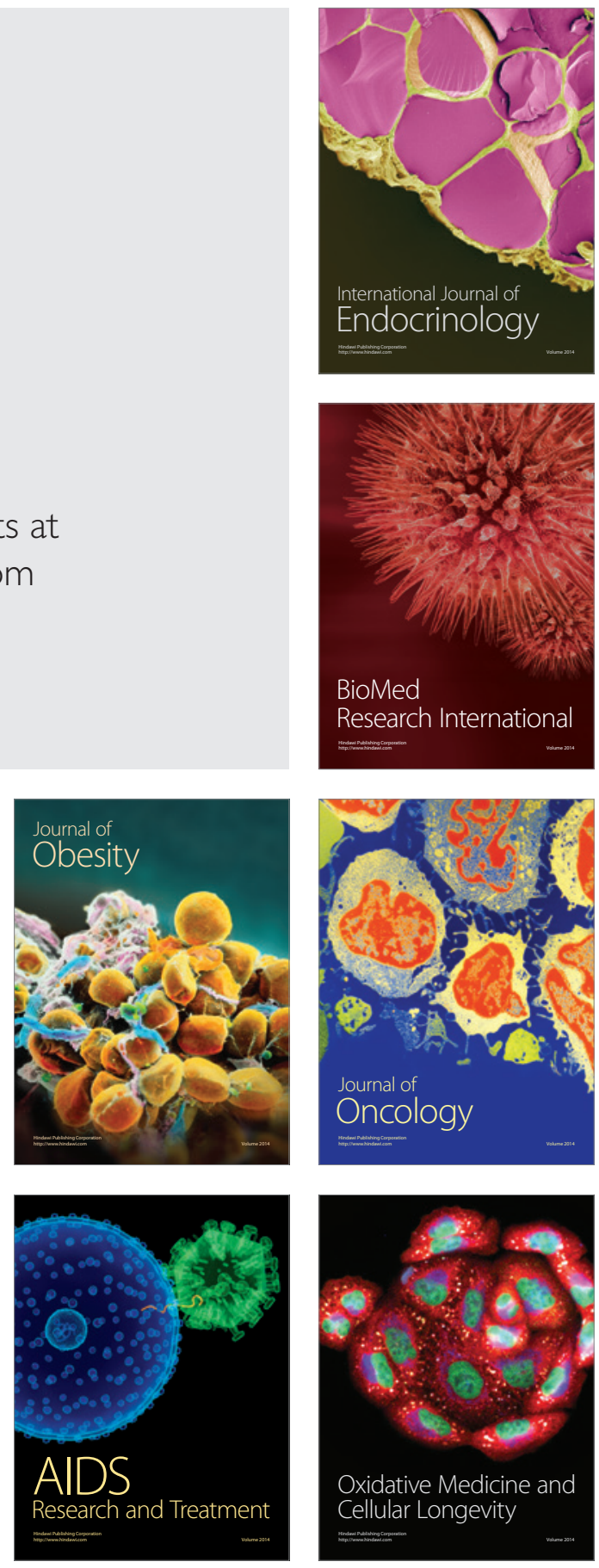